\title{
Interleukin-6 is the strongest predictor of 30-day mortality in patients with cardiogenic shock due to myocardial infarction
}

\author{
René P Andrié ${ }^{*}$, Ulrich M Becher ${ }^{\dagger}$, Ricarda Frommold, Vedat Tiyerili, Jan W Schrickel, Georg Nickenig and
}

Jörg O Schwab

\begin{abstract}
Introduction: Cardiogenic shock (CS) remains the leading cause of death in patients hospitalized for myocardial infarction (MI). Systemic inflammation with inappropriate vasodilatation is observed in many patients with CS and may contribute to an excess mortality rate. The purpose of this study was to determine the predictive role of serial measurements of Nt-proBNP, interleukin-6 (IL-6), and procalcitonin (PCT) for 30-day mortality in patients with CS due to Ml.
\end{abstract}

Methods: The present study is a prospective single-center study including 87 patients with MI complicated by CS treated with acute revascularization and intraaortic balloon counterpulsation (IABP) support. Predictive values of plasma levels at admission $\left(T_{0}\right)$, after 24 hours $\left(T_{1}\right)$, and after 72 hours $\left(T_{2}\right)$ were examined according to 30-day mortality.

Results: Significant differences between survivors $(n=59)$ and nonsurvivors $(n=28)$ were seen for Nt-proBNP at $T_{0}$, for IL-6 at $T_{0}$ and $T_{1}$, and for PCT at $T_{1}$ and $T_{2}$. According to ROC analyses, the highest accuracy predicting 30-day mortality was seen at $T_{0}$ for IL-6, at $T_{1}$ for $P C T$, and at $T_{2}$ for $P C T$. In univariate analysis, significant values were found for Nt-proBNP at $T_{1}$, and for IL-6 and PCT at all points in time. Within the multivariate analysis, age, creatinine, and IL-6 were significant determinants of 30-day mortality, in which IL-6 showed the highest level of significance.

Conclusions: In patients with MI complicated by CS, IL-6 represented a reliable independent early prognostic marker of 30-day mortality. PCT revealed a significant value at later points in time, whereas Nt-proBNP seemed to be of lower relevance.

\section{Introduction}

Cardiogenic shock (CS) complicating acute myocardial infarction (AMI) occurs in $5 \%$ to $10 \%$ of hospitalized patients and is the leading cause of intrahospital mortality after AMI $[1,2]$. Early revascularization of the infarctrelated artery is the fundamental step in therapeutic strategies and has been shown to improve long-term survival in patients with CS $[3,4]$. However, some patients fail to show clinical and hemodynamic improvement, with a poor prognosis despite successful immediate revascularization.

\footnotetext{
* Correspondence: Rene.Andrie@ukb.uni-bonn.de

† Contributed equally

Department of Cardiology, University of Bonn, Sigmund-Freud-Str. 25, 53105 Bonn, Germany
}

(c) 2012 Andrié et al.; licensee BioMed Central Ltd. This is an open access article distributed under the terms of the Creative Commons

In the classic pathophysiologic view, $\mathrm{CS}$ is the result of temporary and permanent disorders in the circulatory system [5]. New irreversible injury, reversible ischemia, and damage from prior infarction contribute to left ventricular dysfunction. N-terminal-pro-B-type natriuretic peptide (Nt-proBNP) is used for the early diagnosis of heart failure (HF) in patients with acute dyspnea [6]. In patients with chronic HF and AMI, Nt-proBNP is a reliable predictor of increased mortality [7]. In addition, elevated BNP levels in patients with septic shock are indicative of septic cardiomyopathy [8].

Systemic inflammation with inappropriate vasodilatation, as evidenced by a normal to low range of systemic vascular resistance, is observed in many patients with CS 
and may contribute to an excess mortality rate [9]. Accordingly, it has been postulated that CS causes a systemic inflammatory response syndrome (SIRS) by the release of pro-inflammatory mediators like interleukin-6 (IL-6) and tumor necrosis factor alpha (TNF- $\alpha$ ) [5]. Signs of systemic inflammation such as fever, leukocytosis, and elevated acute-phase reactants are frequently observed in patients with AMI and CS. High levels of systemic inflammation seem to be associated with impaired survival despite early revascularization [5]. It has been shown that patients with CS and multiorgan failure (MOF) exhibit concentrations of IL- 6 of the same magnitude as do patients with septic shock $[10,11]$

Procalcitonin (PCT) is a well-established biomarker for the diagnosis of sepsis [12]. PCT reflects the severity of bacterial infection and is used to monitor progression of infection into sepsis, severe sepsis, or septic shock. Moreover, PCT is used to measure the activity of the systemic inflammatory response [12]. The increase of PCT in patients with sepsis correlates with mortality [12]. A limited number of studies have reported that increased levels of PCT are related to AMI $[13,14]$.

In the present study, we analyzed the relation between plasma levels of Nt-proBNP, IL-6, and PCT at different points in time early after admission and 30-day mortality in patients with CS due to AMI, treated with immediate revascularization and IABP support. Moreover, central determinants of organ failure, hemodynamics, and revascularization were analyzed in relation to short-term prognosis and to levels of Nt-proBNP, IL-6, and PCT.

\section{Materials and methods Subjects}

The present study is a prospective observational singlecenter study at a university hospital. Between 2008 and 2010, 87 patients with AMI complicated by CS at admission were included. The study complies with the Declaration of Helsinki and was approved by the local medical ethics committee. Patients or, in case of unconsciousness, relatives signed a consent form. Underlying causes of CS were categorized as ST-elevation myocardial infarction (STEMI) and non-ST-elevation myocardial infarction (NSTEMI). CS was defined by the presence of one of the following criteria: (a) peak systolic pressure $<90 \mathrm{~mm} \mathrm{Hg}$ for $>30$ minutes after the correction of hypovolemia, hypoxemia, and acidosis or need for vasopressor and/or inotropic therapy; (b) signs of organ hypoperfusion such as oliguria/anuria, changes in mental state, or elevated serum lactate concentrations $(>2.0 \mathrm{mM})$. Patients with ongoing cardiopulmonary resuscitation (CPR) at admission were excluded from the study. Further exclusion criteria were age $<18$ years, immunosuppressive therapy, preexisting infectious diseases, mechanical assist devices other than an intraaortic balloon counterpulsation (IABP), mechanical cardiac complications, and coronary artery bypass grafting (CABG) or any surgery in the last 4 weeks before onset of shock.

All patients were taken directly to the cardiac catheterization laboratory for angiography. All patients had undergone implantation of an IABP (Datascope System CS100 and CS100i, Datascope, Oakland, NJ, USA).

Based on the primary outcome variable all-cause mortality at day 30 , analyses were performed to identify differences between survivors and nonsurvivors and predictors of worse outcome.

\section{Hemodynamic measurements}

Stroke volume (SV) and left ventricular ejection fraction (EF) were quantified invasively with levocardiography. If levocardiography could not be performed, EF was quantified with echocardiography. Cardiac output (CO) (L/min) was calculated as $\mathrm{SV} \times$ heart rate. Cardiac power output (CPO) (W) was calculated as mean arterial pressure $(\mathrm{MAP}) \times \mathrm{CO} / 451$, left ventricular work $(\mathrm{LVW})$ as (MAP left ventricular end-diastolic pressure (LVEDP)) $\times \mathrm{CO} \times$ $0.0136(\mathrm{~kg}-\mathrm{m} / \mathrm{min})$, and systemic vascular resistance (SVR) (dyne $\left.\mathrm{s} / \mathrm{cm}^{5}\right)$ as $80 \times($ MAP - central venous pressure $(\mathrm{CVP})) / \mathrm{CO}$. Left ventricular work index (LVWI) $(\mathrm{kg}-\mathrm{m} /$ min $\left.\times \mathrm{m}^{2}\right)$, cardiac power index $(\mathrm{CPI})\left(\mathrm{W} / \mathrm{m}^{2}\right)$, and systemic vascular resistance index (SVRI) (dyne $\mathrm{s} / \mathrm{cm}^{5} / \mathrm{m}^{2}$ ) were computed by substituting $\mathrm{CO}$ with $\mathrm{CI}$ in the respective formulas. Stroke work (SW) (g-m) was calculated as $($ MAP - LVEDP) $\times 0.0136 \times$ SV. Stroke work index $(S W I)$ $\left(\mathrm{g}-\mathrm{m} / \mathrm{m}^{2}\right)$ was determined by $\mathrm{SW} /$ body surface area. Microcirculatory power index (micPI) was calculated as $\mathrm{CI} \times(\mathrm{MAP}-\mathrm{CVP}) \times$ Hkt-factor .

\section{Blood sampling}

The first blood sample $\left(\mathrm{T}_{0}\right)$ was taken immediately after admission. The second blood sample $\left(\mathrm{T}_{1}\right)$ was taken after 24 hours, and the third blood sample $\left(\mathrm{T}_{2}\right)$, after 72 hours. Nt-proBNP (Siemens Healthcare Diagnostics GmbH, Munich, Germany), IL-6 (Siemens Healthcare Diagnostics $\mathrm{GmbH}$ ) and PCT (Roche Diagnostics GmbH, Mannheim, Germany) were measured immediately. Further routine laboratory parameters were quantified by using commercially available assays.

\section{Organ failure}

Acute renal failure was defined as an increase of the serum creatinine concentration $>2.5 \mathrm{mg} / \mathrm{dl}$, an increase in creatinine $>25 \%$ from baseline, a diuresis $<500 \mathrm{ml} / 24$ hours, or need for hemofiltration. Estimated glomerular filtration rate (eGFR) was calculated by using the Cockroft and Gault formula. Systemic inflammatory response syndrome (SIRS) was defined by approved criteria [5]. 
Multiorgan failure (MOF) was defined as presence of two or more organ failures, other than cardiovascular. As scoring system of ICU mortality the APACHE II score was used.

\section{Statistical analysis}

Continuous variables are expressed as mean \pm standard deviation (SD) if normally distributed and as median (interquartile range) if not normally distributed. Continuous variables were tested for normal distribution with the use of the Kolmogorov-Smirnov test. The Student $t$ test was performed for normally distributed continuous variables, and the Mann-Whitney $U$ test for nonnormally distributed continuous variables. Testing for homogeneity of variance was performed with the Levene test. Categoric variables are given as frequencies and percentages, and the $\chi^{2}$ test with the Fisher Exact test was used for data analysis. Receiver operating characteristics (ROC) curves were performed to determine cut-off levels of Nt-proBNP, IL-6, and PCT, with the highest sensitivity and specificity predicting 30-day mortality. The cumulative survival plots were estimated with the Kaplan-Meier method. Survival in groups was compared with the logrank test. Univariate Cox regression analysis was performed to identify significant independent predictors of outcome.

For multivariate analysis, age, CPI, mean dose of catecholamines, lactate, creatinine, and IL- 6 or PCT were included. For this analysis, a backward stepwise selection method was used. Results are reported as adjusted hazard ratio (HR) with $95 \%$ confidence interval (CI). A two-sided $P$ value less 0.05 was considered statistically significant. Statistical analyses were performed by using SPSS software version 18.0 (SPSS, Chicago, IL, USA).

\section{Results}

\section{Primary end point 30-day mortality}

The overall 30-day mortality was $32.2 \%$ ( $n=28$ nonsurvivors, $n=59$ survivors). No patient died in the catheterization laboratory. Six patients died before $\mathrm{T}_{1}$, and six further patients died before $\mathrm{T}_{2}$. Main cause of death was MOF. Mortalities showed no significant differences in STEMI versus NSTEMI patients, male versus female patients, or patients older than 75 years versus 75 years or younger (data not shown).

\section{Baseline patient characteristics}

Baseline patient characteristics of survivors and nonsurvivors are shown in Table 1 . Age, percentage of patients receiving mechanical ventilation, serum lactate levels, hemoglobin, and serum creatinine differed significantly between the nonsurvivor and survivor groups. There were no further differences concerning patient characteristics and demographic data.

\section{Diagnostic and therapeutic characteristics}

All patients underwent coronary angiography immediately after admission. Diagnostic and therapeutic characteristics are summarized in Table 2. Percutaneous coronary intervention (PCI) was performed technically successfully in 77 (96.3\%) patients, defined by a patent vessel with TIMI $\geq 2$ flow, $<50 \%$ residual stenosis, and no emergency CABG. Rates of successful PCI were similar in both groups (Table 2). The most common reasons for not attempting revascularization/surgery were a high-risk operation due to low ejection fraction, irreversible MOF, and coronary vessels not suitable for PCI or CABG. Rate of periinterventional CPR was significantly elevated in the nonsurvivor group.

\section{Hemodynamic parameters and catecholamine support}

Values of hemodynamic measurements at admission are illustrated in Table 3. For CPI, a significant difference was observed. In addition, MAP and systolic BP were reduced within the nonsurvivor group, whereas heart rate and maximal CVP within the first 24 hours were elevated in this group. Patients $(68 ; 78.2 \%)$ required supportive catecholamine therapy within the first 24 hours, the more in the nonsurvivor group (Table 3).

\section{Predictive value of Nt-proBNP, IL-6, and PCT for 30-day mortality}

Main purpose of the present study was to determine the predictive value of serial measurements of $\mathrm{Nt}$-proBNP, IL-6, and PCT for 30-day mortality. Medians (interquartile ranges) in all patients accounted for Nt-proBNP, 4,065 $(1,147 / 9,775) \mathrm{pg} / \mathrm{ml}$ at $\mathrm{T}_{0}, 3,588(1,667 / 7,376) \mathrm{pg} / \mathrm{ml}$ at $\mathrm{T}_{1}$, and $2,409(1,082 / 5,235) \mathrm{pg} / \mathrm{ml}$ at $\mathrm{T}_{2}$; IL-6, $74.7(18.1 / 255.5)$ $\mathrm{pg} / \mathrm{ml}$ at $\mathrm{T}_{0}, 46.5(28.2 / 136.0) \mathrm{pg} / \mathrm{ml}$ at $\mathrm{T}_{1}$, and $26.8(10.4 /$ 83.4) $\mathrm{pg} / \mathrm{ml}$ at $\mathrm{T}_{2}$; PCT, $0.25(0.10 / 1.40) \mu \mathrm{g} / \mathrm{L}$ at $\mathrm{T}_{0}, 0.53$ $(0.10 / 1.68) \mu \mathrm{g} / \mathrm{L}$ at $\mathrm{T}_{1}$, and $0.43(0.15 / 0.90) \mu \mathrm{g} / \mathrm{L}$ at $\mathrm{T}_{2}$. Significant differences between survivors and nonsurvivors were seen for Nt-proBNP at $\mathrm{T}_{1}(2,831$ versus $6,871 \mathrm{pg} / \mathrm{ml}$; $P=0.024)$, for IL-6 at $\mathrm{T}_{0}(30.7$ versus $424.0 \mathrm{pg} / \mathrm{ml} ; P<$ $0.0001)$, and $\mathrm{T}_{1}$ (41.9 versus $\left.79.1 \mathrm{pg} / \mathrm{ml} ; P=0.015\right)$, and for PCT at $\mathrm{T}_{1}(0.46$ versus $2.42 \mu \mathrm{g} / \mathrm{L} ; \mathrm{p}=0.001)$ and $\mathrm{T}_{2}(0.32$ versus $1.44 \mu \mathrm{g} / \mathrm{L} ; P=0.001$ ) (Figure 1 ). In contrast, for CRP, no statistical differences were seen (data not shown).

ROC curves calculated for Nt-proBNP, IL-6, and PCT at $\mathrm{T}_{0}, \mathrm{~T}_{1}$, and $\mathrm{T}_{2}$ are illustrated in Figure 2 . At the earliest point in time, $\mathrm{T}_{0}$, only IL- 6 was predictive of 30-day mortality; at $\mathrm{T}_{1}$, IL- 6 and PCT showed significant $P$ values, at $\mathrm{T}_{2} \mathrm{PCT}$ and $\mathrm{Nt}$-proBNP were predictive of mortality. Comparing the area under the curve of the parameters at each point in time, the highest accuracy in predicting 30-day mortality was seen for IL-6 at $\mathrm{T}_{0}$, for PCT at $\mathrm{T}_{1}$, and for PCT at $\mathrm{T}_{2}$ (Figure 2). Notably, the highest level of significance was found for IL-6 at $\mathrm{T}_{0}$. Based on these analyses, corresponding cut-off levels 
Table 1 Baseline characteristics of study population according to outcome

\begin{tabular}{|c|c|c|c|c|}
\hline & All patients $(n=87)$ & Survivors $(n=59)$ & Nonsurvivors $(n=28)$ & $P$ value \\
\hline Age (years) & $67.78 \pm 13.4$ & $64.68 \pm 14.3$ & $74.32 \pm 8.4$ & $<0.0001$ \\
\hline Age $>75$ years (\%) & $35(40.2)$ & $19(32.2)$ & $14(50.0)$ & 0.156 \\
\hline Male (\%) & $68(78.2)$ & $46(78.0)$ & $22(78.6)$ & 0.949 \\
\hline STEMI/NSTEMI (\%) & 44/43 (50.6/49.4) & $30 / 29(50.8 / 49.2)$ & $14 / 14(50.0 / 50.0)$ & 0.941 \\
\hline Diabetes (\%) & $29(33.3)$ & $21(35.6)$ & $8(28.6)$ & 0.629 \\
\hline Hypertension (\%) & $53(60.9)$ & $37(62.7)$ & $16(57.1)$ & 0.645 \\
\hline Dyslipidemia (\%) & $43(49.4)$ & $31(52.5)$ & $12(42.9)$ & 0.493 \\
\hline Smoker (\%) & $31(35.6)$ & $23(39.0)$ & $8(28.6)$ & 0.473 \\
\hline Obesity (\%) & $20(23.0)$ & $15(25.4)$ & $5(17.9)$ & 0.587 \\
\hline BMI $\left(\mathrm{kg} / \mathrm{m}^{2}\right)$ & $27.6 \pm 5.5$ & $27.7 \pm 5.8$ & $27.2 \pm 4.8$ & 0.739 \\
\hline Family history (\%) & $11(12.6)$ & $7(11.9)$ & $4(14.3)$ & 0.741 \\
\hline CAD (\%) & $42(48.3)$ & $28(47.5)$ & $14(50.0)$ & 0.825 \\
\hline Previous MI (\%) & $25(28.7)$ & $17(28.8)$ & $8(28.6)$ & 0.981 \\
\hline Previous PCI (\%) & $24(27.6)$ & $17(28.8)$ & $7(25.0)$ & 0.801 \\
\hline Previous CABG (\%) & $6(6.9)$ & $4(6.8)$ & $2(7.1)$ & 0.950 \\
\hline Chronic heart failure (\%) & $11(12.6)$ & $8(13.6)$ & $3(10.7)$ & 0.978 \\
\hline Previous stroke (\%) & $10(11.5)$ & $8(13.6)$ & $2(7.1)$ & 0.490 \\
\hline Chronic renal failure (\%) & $10(11.5)$ & $5(8.5)$ & $5(17.9)$ & 0.281 \\
\hline Mechanical ventilation at admission (\%) & $43(49.4)$ & $28(47.5)$ & $15(53.6)$ & 0.651 \\
\hline Mechanical ventilation at any time (\%) & $62(71.3)$ & $36(61.0)$ & $26(91.3)$ & 0.013 \\
\hline Transferred patients (\%) & $39(44.8)$ & $29(49.2)$ & $10(35.7)$ & 0.259 \\
\hline Preclinical CPR (\%) & $23(26.4)$ & $16(27.1)$ & $7(25.0)$ & 0.834 \\
\hline Serum creatinine (mg/dl) & $1.44(1.17 / 2.10)$ & $1.34(1.09 / 1.58)$ & $1.99(1.45 / 3.45)$ & $<0.0001$ \\
\hline Hemoglobin $(\mathrm{g} / \mathrm{dl})$ & $12.5(10.5 / 14.4)$ & $13.1(11.1 / 14.9)$ & $10.8(10.0 / 13.5)$ & 0.034 \\
\hline Troponin I (ng/ml) & $14.7(2.9 / 62.5)$ & $9.1(1.9 / 54.4)$ & $21.0(9.0 / 77.0)$ & 0.069 \\
\hline Blood glucose (mg/dl) & $199.0 \pm 129.9$ & $201.3 \pm 142.1$ & $193.3 \pm 96.5$ & 0.942 \\
\hline Serum lactate $(\mathrm{m} M)$ & $1.9(1.1 / 6.0)$ & $1.4(1.1 / 3.2)$ & $5.8(1.6 / 12.7)$ & 0.008 \\
\hline
\end{tabular}

Values are expressed as $n(\%)$, or mean \pm SD. BMI, body mass index; CABG, coronary artery bypass grafting; CAD, coronary artery disease; CPR, cardiopulmonary resuscitation; MI, myocardial infarction; NSTEMI, non-ST-elevation myocardial infarction; PCI, percutaneous coronary intervention; STEMI, ST-elevation myocardial infarction.

with highest sensitivity and specificity were calculated: $\mathrm{T}_{0}$ IL-6, $307 \mathrm{pg} / \mathrm{ml}$ (sensitivity, $57.1 \%$; specificity, $97.7 \%$ ); $\mathrm{T}_{1}$ PCT, $1.23 \mu \mathrm{g} / \mathrm{L}$ (sensitivity, 83.3\%; specificity, 81.4\%); $\mathrm{T}_{2}$ PCT, $0.71 \mu \mathrm{g} / \mathrm{L}$ (sensitivity, 90.0\%; specificity, 82.9\%). Based on these cut-off levels, 30-day survival rates of patients according to Kaplan-Meier analyses differed highly significantly (Figure 3). Survival of patients with IL-6 levels below the cut-off value was significantly improved compared with that of patients with IL-6 levels above the cut-off value, irrespective of the presence of SIRS $(P<0.05)$.

\section{Organ failure as predictor of 30-day mortality}

Acute kidney injury (AKI) occurred in 31 (35.6\%) patients. AKI appeared significantly more frequent in nonsurvivors (67.9\%) compared with survivors $(20.7 \% ; P<0.0001)$. Serum creatinine at admission $(1.99(1.45 / 3.45) \mathrm{mg} / \mathrm{dl}$ versus $1.34(1.09 / 1.58) \mathrm{mg} / \mathrm{dl})$ and eGFR $(38.2 \pm 19.4 \mathrm{ml} / \mathrm{min}$ versus $67.7 \pm 31.5 \mathrm{ml} / \mathrm{min}$ ) after the first 24 hours also differed significantly between the groups $(P<0.0001)$. The incidence of MOF was increased dramatically in the nonsurvivor group (60.7\% versus $6.8 \%$; $P<0.0001$ ). According to Kaplan-Meier analyses, the overall 30-day survival rate of patients with MOF was markedly lower than that of patients without MOF (15.0\% versus $84.8 \%$; $P$ $<0.0001$ by log-rank test). The overall survival rate of patients with an APACHE II score above the median was in trend lower than that of patients below this cutoff (62.9\% versus $81.8 \% ; P=0.065)$. Initial serum lactate as a marker for organ hypoperfusion was clearly elevated within the nonsurvivor group $(5.8(1.6 / 12.7) \mathrm{m} M$ versus $1.4(1.1 /$ 3.2) $\mathrm{m} M ; P<0.01)$.

\section{Univariate and multivariate analyses of predictors for 30-day mortality}

In univariate analysis, significant values were found for Nt-proBNP at $\mathrm{T}_{1}$, for IL-6 at all points in time, and for PCT also at all points in time (Table 4). Further significant predictors are shown in Table 4. Within the multivariate analysis including age, $\mathrm{CPI}$ at admission, total mean dose of catecholamines within first 24 hours, lactate at admission, creatinine at admission, IL- 6 at 
Table 2 Procedural characteristics of study population according to outcome

\begin{tabular}{|c|c|c|c|c|}
\hline & All patients $(n=87)$ & Survivors $(n=59)$ & Nonsurvivors $(n=28)$ & $P$ value \\
\hline EF (\%) & $35.2 \pm 11.6$ & $34.7 \pm 11.6$ & $36.4 \pm 11.9$ & 0.548 \\
\hline$E F<30 \%(\%)$ & $24(27.6)$ & $16(27.1)$ & $9(32.1)$ & 0.789 \\
\hline Three-vessel disease (\%) & $51(58.6)$ & $34(57.6)$ & $17(60.7)$ & 0.814 \\
\hline \multicolumn{5}{|l|}{ Infarct artery } \\
\hline Left main (\%) & $6(6.9)$ & $4(6.8)$ & $2(7.1)$ & 0.950 \\
\hline Left anterior descending (\%) & $43(49.4)$ & $29(49.2)$ & $14(49.2)$ & 0.941 \\
\hline Right coronary artery (\%) & $21(24.1)$ & $13(22.0)$ & $8(28.6)$ & 0.691 \\
\hline Left circumflex (\%) & $24(27.6)$ & $15(25.4)$ & $9(32.1)$ & 0.690 \\
\hline Bypass graft (\%) & $1(1.1)$ & $1(1.7)$ & $0(0)$ & 0.488 \\
\hline Revascularization procedure (PCl or CABG) (\%) & $82(94.3)$ & $57(96.6)$ & $25(89.3)$ & 0.323 \\
\hline PCl left main (\%) & $12(13.8)$ & $10(16.9)$ & $2(7.1)$ & 0.323 \\
\hline PCl success (\%) & $77(96.3)$ & $55(96.5)$ & $22(95.7)$ & 0.858 \\
\hline CABG (\%) & $2(2.3)$ & $0(0 \%)$ & $2(7.1)$ & 0.091 \\
\hline Number of treated vessels & $1.26 \pm 0.54$ & $1.26 \pm 0.48$ & $1.25 \pm 0.68$ & 0.932 \\
\hline Time to reperfusion (hours) & $6.1 \pm 5.2$ & $5.6 \pm 4.6$ & $7.3 \pm 5.9$ & 0.072 \\
\hline Duration of IABP support (hours) & $54.5 \pm 24.0$ & $55.4 \pm 20.8$ & $52.1 \pm 31.3$ & 0.654 \\
\hline TIMI flow before $\mathrm{PCl}$ & $0.51 \pm 0.67$ & $0.51 \pm 0.67$ & $0.50 \pm 0.71$ & 0.958 \\
\hline TIMI flow after $\mathrm{PCl}$ & $2.77 \pm 0.57$ & $2.82 \pm 0.51$ & $2.67 \pm 0.70$ & 0.343 \\
\hline CPR periinterventional (\%) & $12(13.8)$ & $5(8.5)$ & $7(25.0)$ & 0.040 \\
\hline
\end{tabular}

Values are expressed as $n(\%)$, or mean $\pm \mathrm{SD}$. CABG, coronary artery bypass graft; CPR, cardiopulmonary resuscitation; EF, ejection fraction; IABP, intraaortic balloon counterpulsation; $\mathrm{PCl}$, percutaneous coronary intervention; TIMI, thrombolysis in myocardial infarction.

Table 3 Hemodynamics and catecholamine support according to outcome

\begin{tabular}{|c|c|c|c|c|}
\hline & All patients $(n=87)$ & Survivors $(n=59)$ & Nonsurvivors $(n=28)$ & $P$ value \\
\hline \multicolumn{5}{|l|}{ Hemodynamics } \\
\hline $\mathrm{Cl}\left(\mathrm{L} / \mathrm{min} / \mathrm{m}^{2}\right)$ & $2.15 \pm 0.83$ & $2.16 \pm 0.78$ & $2.12 \pm 0.93$ & 0.825 \\
\hline $\mathrm{CPI}\left(\mathrm{W} / \mathrm{m}^{2}\right)$ & $0.35 \pm 0.15$ & $0.37 \pm 0.15$ & $0.30 \pm 0.15$ & 0.041 \\
\hline $\mathrm{CPO}(\mathrm{W})$ & $0.67 \pm 0.26$ & $0.70 \pm 0.27$ & $0.60 \pm 0.25$ & 0.102 \\
\hline Microcirculatory PI & $97.51 \pm 46.17$ & $101.74 \pm 43.08$ & $86.23 \pm 53.22$ & 0.181 \\
\hline $\mathrm{SV}(\mathrm{ml})$ & $52.6 \pm 16.5$ & $54.7 \pm 16.8$ & $48.1 \pm 15.4$ & 0.078 \\
\hline $\mathrm{SVI}\left(\mathrm{ml} / \mathrm{m}^{2}\right)$ & $26.8 \pm 9.4$ & $28.0 \pm 9.0$ & $24.3 \pm 9.8$ & 0.105 \\
\hline sW (g m) & $37.5 \pm 18.5$ & $39.4 \pm 18.6$ & $31.7 \pm 17.5$ & 0.121 \\
\hline SWI $\left(\mathrm{g} \mathrm{m} / \mathrm{m}^{2}\right)$ & $19.1 \pm 10.2$ & $20.2 \pm 10.1$ & $16.0 \pm 10.2$ & 0.137 \\
\hline LWW (kg m/min) & $2.88 \pm 1.35$ & $2.97 \pm 1.35$ & $2.60 \pm 1.37$ & 0.327 \\
\hline LVWI (kg m/min/m²) & $1.47 \pm 0.77$ & $1.53 \pm 0.74$ & $1.30 \pm 0.84$ & 0.320 \\
\hline SVR (dynes sec/cm ${ }^{5}$ ) & $1,251.8 \pm 672.9$ & $1,285.3 \pm 705.6$ & $1,146.6 \pm 566.9$ & 0.444 \\
\hline SVRI (dynes sec/ $\mathrm{cm}^{5} / \mathrm{m}^{2}$ ) & $2,281.6 \pm 898.2$ & $2,302.9 \pm 894.2$ & $2,216.2 \pm 938.8$ & 0.756 \\
\hline MAP $(m m ~ H g)$ & $71.1 \pm 15.0$ & $74.8 \pm 13.7$ & $63.8 \pm 14.9$ & 0.002 \\
\hline Min. MAP $(\mathrm{mm} \mathrm{Hg})$ day 1 & $55.1 \pm 13.1$ & $58.9 \pm 10.9$ & $45.8 \pm 13.7$ & 0.001 \\
\hline Systolic BP (mm Hg) & $94.8 \pm 22.7$ & $98.6 \pm 21.7$ & $85.5 \pm 23.0$ & 0.036 \\
\hline Min. systolic BP (mm Hg) day 1 & $70.9 \pm 17.7$ & $75.8 \pm 15.7$ & $59.0 \pm 16.8$ & 0.001 \\
\hline LVEDP $(\mathrm{mm} \mathrm{Hg})$ & $23.1 \pm 8.9$ & $22.9 \pm 9.3$ & $23.7 \pm 8.1$ & 0.748 \\
\hline CVP $(\mathrm{mm} \mathrm{Hg})$ & $12.7 \pm 5.8$ & $12.2 \pm 5.0$ & $13.8 \pm 7.6$ & 0.416 \\
\hline Max. CVP (mm Hg) day 1 & $19.0 \pm 8.3$ & $17.2 \pm 7.4$ & $23.9 \pm 8.9$ & 0.008 \\
\hline HR (beats/min) & $82.1 \pm 21.2$ & $78.7 \pm 19.4$ & $89.4 \pm 23.2$ & 0.043 \\
\hline Min. HR (beats/min) day 1 & $59.0 \pm 17.3$ & $56.4 \pm 13.7$ & $65.5 \pm 23.3$ & 0.115 \\
\hline Max. HR (beats/m) day 1 & $123.2 \pm 25.3$ & $118.8 \pm 23.8$ & $134.0 \pm 26.2$ & 0.032 \\
\hline $\mathrm{ScVO}_{2}(\%)$ & $66.3 \pm 16.9$ & $67.6 \pm 16.5$ & $63.2 \pm 18.0$ & 0.378 \\
\hline Min. Scvo $2(\%)$ day 1 & $56.3 \pm 13.5$ & $56.2 \pm 12.4$ & $56.7 \pm 16.3$ & 0.905 \\
\hline \multicolumn{5}{|l|}{ Inotropic and vasopressor support } \\
\hline Catecholamine use (\%) & $68(78.2 \%)$ & $43(72.9)$ & $25(89.3)$ & 0.101 \\
\hline
\end{tabular}


Table 3 Hemodynamics and catecholamine support according to outcome (Continued)

\begin{tabular}{|c|c|c|c|c|}
\hline Dobutamine use (\%) & $52(59.8)$ & $33(55.9)$ & $20(71.4)$ & 0.240 \\
\hline Mean dose of dobutamine ( $\mu \mathrm{g} / \mathrm{min})$ day 1 & $500(0 / 975)$ & $250(0 / 700)$ & $950(0 / 1,075)$ & 0.021 \\
\hline Norepinephrine use (\%) & $64(73.6)$ & $39(66.1)$ & $25(89.3)$ & 0.036 \\
\hline Epinephrine use (\%) & $25(28.7)$ & $8(13.6)$ & $18(64.3)$ & $<0.0001$ \\
\hline Mean dose of epinephrine $(\mu \mathrm{g} / \mathrm{min})$ day 1 & $0(0 / 0.5)$ & $0(0 / 0)$ & $15(0 / 80)$ & $<0.0001$ \\
\hline Total number of catecholamines & $2.0(1.0 / 2.0)$ & $2.0(0.0 / 2.0)$ & $3.0(2.0 / 3.0)$ & 0.001 \\
\hline Total mean dose of catecholamines ( $\mu \mathrm{g} / \mathrm{min})$ day 1 & $503(0.6 / 1013)$ & $305(0 / 706)$ & $995(165 / 1310)$ & 0.006 \\
\hline
\end{tabular}

Values are expressed as $n(\%)$, mean $\pm \mathrm{SD}$, or median with interquartile range (quartile 1 to quartile 3 ). Beats/min, beats per minute; $\mathrm{BP}$, blood pressure; $\mathrm{Cl}$, cardiac index; $\mathrm{CO}$, cardiac output; CPI, cardiac power index; CPO, cardiac power output; CVP, central venous pressure; HR, heart rate; LVEDP, left ventricular enddiastolic pressure; LVW, left ventricular work; LVWI, left ventricular work index; MAP, mean arterial pressure; max, maximal; min, minimal; Scvo ${ }_{2}$, central venous oxygen saturation; SV, stroke volume; SVI, stroke volume index; SVR, systemic vascular resistance; SVRI, systemic ventricular resistance index; SW, stroke work; SWI, stroke work index.

admission, and PCT at admission, age, creatinine, and IL6 were significant determinants of 30-day mortality in which IL-6 showed the highest level of significance (Table 5).

\section{Discussion}

The aim of the present study was to analyze the predictive value of a broad spectrum of clinical and laboratory parameters in patients with CS due to AMI treated with immediate revascularization. To the best of our knowledge, this is the first prospective investigation in the early phase of AMI and CS analyzing serial measurements of NtproBNP, IL-6, and PCT as predictors of 30-day mortality.

Growing evidence indicates that an aggressive strategy based on immediate coronary revascularization and IABP support is the most effective therapy for CS due to AMI $[2,5]$. Characteristics of our study population were similar to those of the patients undergoing revascularization in the Should We Emergently Revascularize Occluded Coronaries for Cardiogenic Shock (SHOCK) trial [15]. The present study was based on a therapy strategy that included urgent revascularization and support by an IABP. In contrast to the SHOCK trial, the predominant proportion of patients was revascularized by PCI with a high success rate and revealed a 30-day mortality of $32 \%$, an incidence lower than that reported in the SHOCK trial [15].

\section{Nt-proBNP, IL-6, and PCT as predictors of outcome}

The measurement of serum levels of natriuretic peptides is established in the diagnosis and follow-up of chronic HF. Maisel et al. [6] showed that BNP may be helpful in

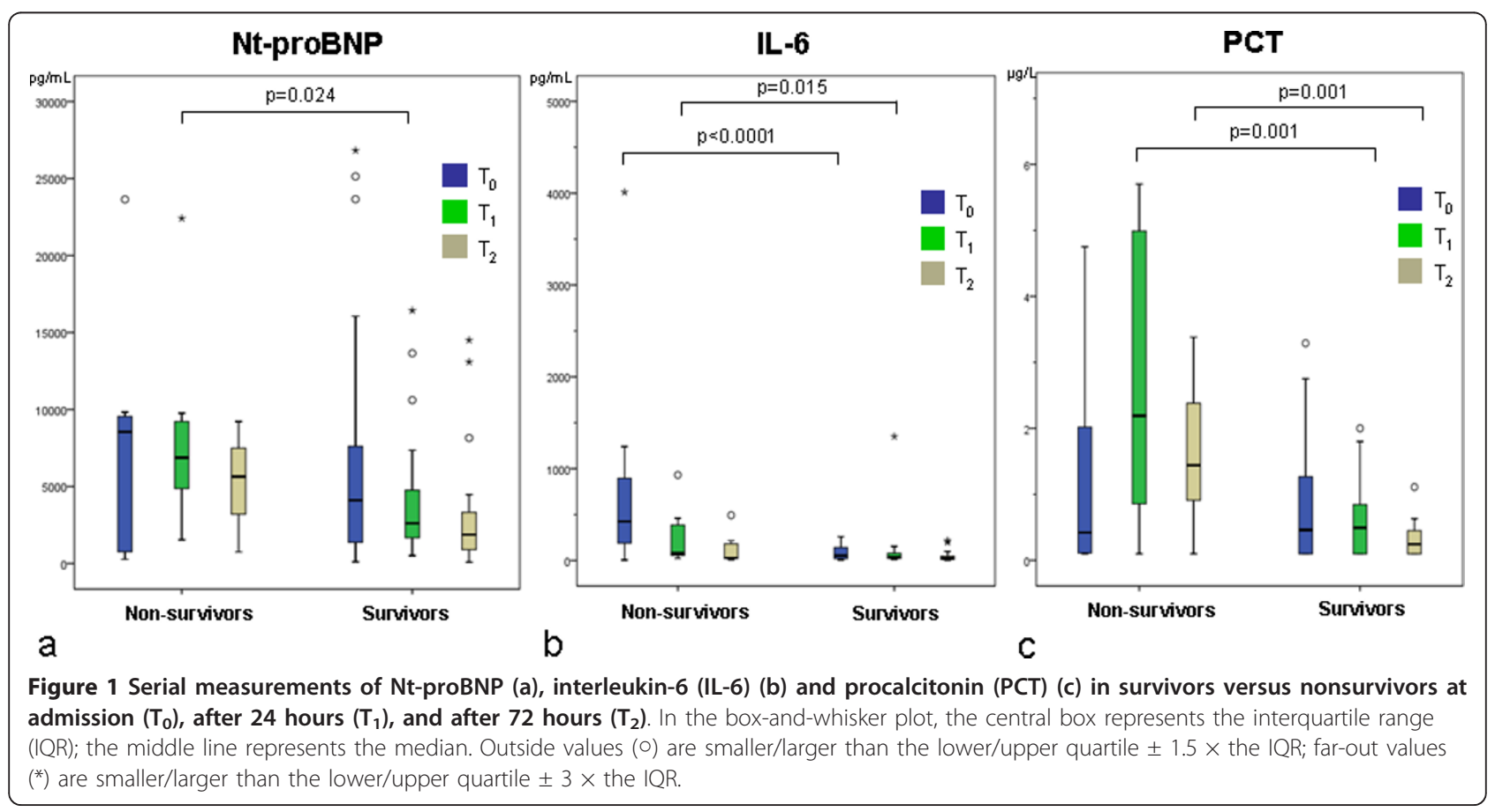




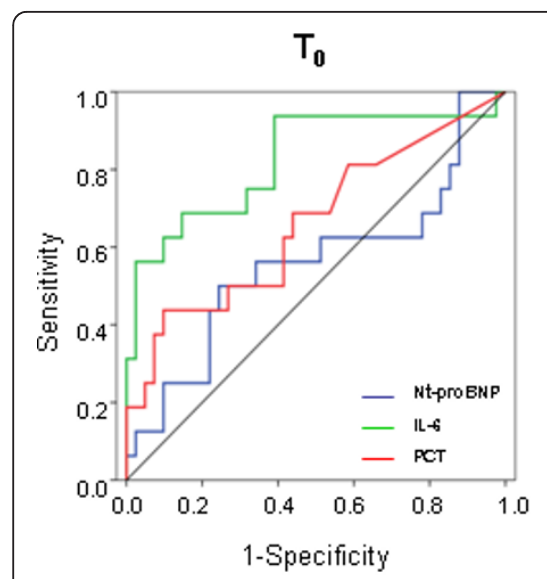

$\begin{array}{lcl}\text { Variable } & \begin{array}{c}\text { Area under } \\ \text { curve }\end{array} & \text { p value } \\ \text { Nt-proBNP } & 0.558 & 0.500 \\ \text { IL-6 } & 0.825 & <0.0001 \\ \text { PCT } & 0.660 & 0.062\end{array}$

a

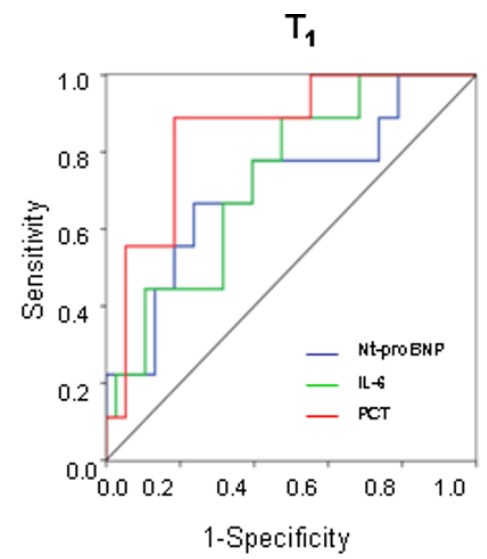

$\begin{array}{lcc}\text { Variable } & \begin{array}{c}\text { Area under } \\ \text { curve }\end{array} & \mathbf{p} \text { value } \\ \text { Nt-proBNP } & 0.711 & 0.052 \\ \text { IL-6 } & 0.731 & 0.033 \\ \text { PCT } & 0.854 & 0.001\end{array}$

b

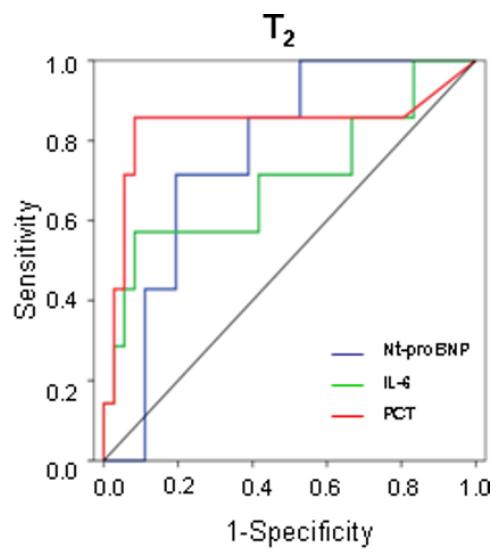

$\begin{array}{lcc}\text { Variable } & \begin{array}{c}\text { Area under } \\ \text { curve }\end{array} & \boldsymbol{p} \text { value } \\ \text { Nt-proBNP } & 0.766 & 0.028 \\ \text { IL-6 } & 0.702 & 0.093 \\ \text { PCT } & 0.835 & 0.005\end{array}$

C

Figure 2 Receiver operating characteristic (ROC) curves for 30-day mortality. Analysis of 30-day mortality calculated from values of NtproBNP, interleukin-6 (IL-6), and procalcitonin (PCT) at admission ( $\left.T_{0}\right)(\mathbf{a})$, after 24 hours ( $\left.T_{1}\right)$ (b), and after 72 hours ( $\left.T_{2}\right)$ (c). ROC curve analysis with area under the curve and significance levels.

diagnosing acute HF in the emergency setting. Moreover, Nt-proBNP has been suggested as a useful marker of high risk in acute myocardial infarction. Higher baseline levels of BNP in patients presenting with STEMI were associated with impairment of reperfusion after fibrinolytic therapy, whereas patients in the highest
BNP-concentration quartile had an 11-fold risk of dying by 30 days [16]. Similarly, Nt-proBNP was previously shown to be predictive of myocardial damage, development of CS, and short- and long-term mortality $[17,18]$. Data concerning the predictive value of serial NtproBNP measurements in patients with manifest CS due

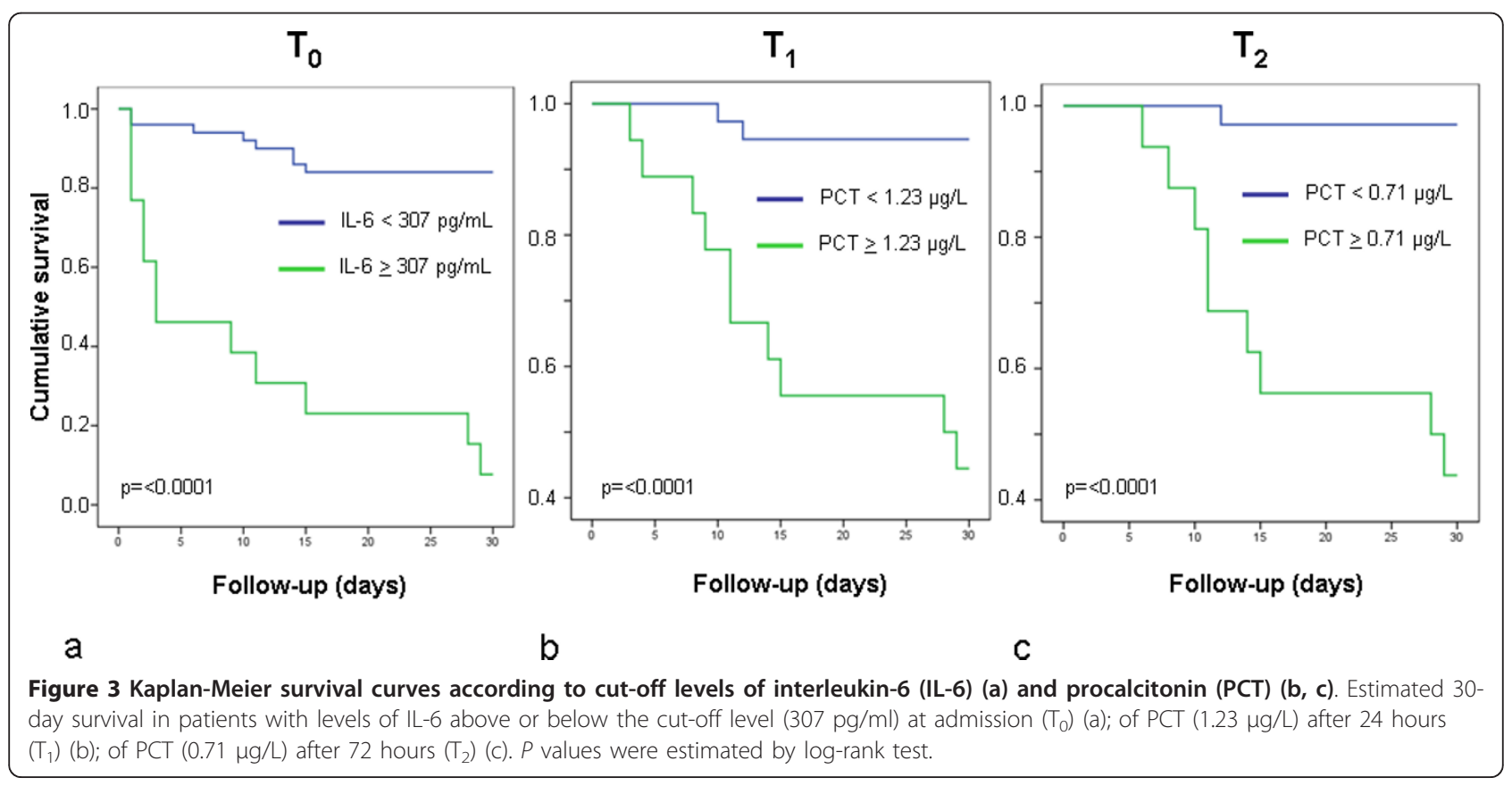




\begin{tabular}{|c|c|c|}
\hline & $\mathrm{HR}(95 \% \mathrm{Cl})$ & $P$ value \\
\hline \multicolumn{3}{|l|}{ Patient characteristics } \\
\hline Age, per 10 years & $1.638(1.174-2.285)$ & 0.004 \\
\hline$E F$, per $5 \%$ & $1.061(0.887-1.269)$ & 0.516 \\
\hline Left main & $2.143(0.504-9.117)$ & 0.302 \\
\hline STEMI & $1.005(0.479-2.108)$ & 0.989 \\
\hline Mechanical ventilation & $1.313(0.625-2.762)$ & 0.472 \\
\hline \multicolumn{3}{|l|}{ Hemodynamics and catecholamines } \\
\hline $\mathrm{CO}, \mathrm{L} / \mathrm{min}$ & $0.986(0.760-1.279)$ & 0.915 \\
\hline $\mathrm{Cl}, \mathrm{L} / \mathrm{min} / \mathrm{m}^{2}$ & $0.934(0.594-1.468)$ & 0.768 \\
\hline $\mathrm{CPI}, 0.1 \mathrm{~W} / \mathrm{m}^{2}$ & $0.766(0.593-0.991)$ & 0.043 \\
\hline $\mathrm{CPO}, 0.1 \mathrm{~W}$ & $0.874(0.747-1.023)$ & 0.094 \\
\hline Microcirculatory $\mathrm{Pl} / 10$ & $0.888(0.795-0.992)$ & 0.036 \\
\hline SVRI, 100 dynes $\mathrm{sec} / \mathrm{cm}^{5} / \mathrm{m}^{2}$ & $0.992(0.937-1.050)$ & 0.776 \\
\hline MAP, $5 \mathrm{~mm} \mathrm{Hg}$ & $0.821(90.726-0.928)$ & 0.002 \\
\hline Heart rate, 5 beats/min & $1.086(1.003-1.176)$ & 0.041 \\
\hline Catecholamine use & $3.073(0.716-13.198)$ & 0.131 \\
\hline Total number of catecholamines & $2.332(1.350-4.029)$ & 0.002 \\
\hline Mean dose of catecholamines, $10 \mu \mathrm{g} / \mathrm{min}$ & $1.014(1.004-1.024)$ & 0.006 \\
\hline \multicolumn{3}{|l|}{ Organ failure } \\
\hline Acute kidney injury & $5.084(2.290-11.290)$ & $<0.0001$ \\
\hline SIRS & $1,412(0.639-3.121)$ & 0.394 \\
\hline MOF & 8.317 (3.754-18.425) & $<0.0001$ \\
\hline Lactate, mM & $1.164(1.086-1.247)$ & $<0.0001$ \\
\hline APACHE $\|>$ Median & $2.390(0.908-6.294)$ & 0.078 \\
\hline \multicolumn{3}{|l|}{ Laboratory measurements } \\
\hline Creatinine $T_{0}, \mathrm{mg} / \mathrm{dl}$ & $1.299(1.092-1.546)$ & 0.003 \\
\hline Creatinine $T_{1}$, mg/dl & $2.155(1.534-3.028)$ & $<0.0001$ \\
\hline Creatinine $T_{2}, \mathrm{mg} / \mathrm{dl}$ & $1.562(0.626-3.901)$ & 0.339 \\
\hline Nt-proBNP $T_{0}, 1,000 \mathrm{pg} / \mathrm{ml}$ & $1.022(0.988-1.056)$ & 0.204 \\
\hline Nt-proBNP $T_{1}, 1,000 \mathrm{pg} / \mathrm{ml}$ & $1.111(1.045-1.182)$ & 0.001 \\
\hline Nt-proBNP $T_{2}, 1,000$ pg/ml & 1.109 (0.959-1.282) & 0.161 \\
\hline $\mathrm{IL}-6 \mathrm{~T}_{0}, 100 \mathrm{pg} / \mathrm{ml}$ & $1.019(1.008 / 1.030)$ & 0.001 \\
\hline IL-6 T1, $100 \mathrm{pg} / \mathrm{ml}$ & $1.134(1.023-1.257)$ & 0.016 \\
\hline$\|-6 \mathrm{~T}_{2}, 100 \mathrm{pg} / \mathrm{ml}$ & $1.550(1.031-2.331)$ & 0.035 \\
\hline$P C T T_{0}, \mu g / L$ & $1.368(1.075-1.741)$ & 0.011 \\
\hline PCT $\mathrm{T}_{1}, \mu \mathrm{g} / \mathrm{L}$ & $1.266(1.122-1.429)$ & $<0.0001$ \\
\hline PCT $T_{2}, \mu \mathrm{g} / \mathrm{L}$ & $2.980(1.687-5.265)$ & $<0.0001$ \\
\hline
\end{tabular}

IL-6, interleukin-6; MOF, multiorgan failure; Nt-proBNP, N-terminal pro-B-type natriuretic peptide; PCT, procalcitonin; SIRS, systemic inflammatory response syndrome; other abbreviations as in Tables 1 through 3.

to AMI are rare. In the present study, the survivor group showed a decline of Nt-proBNP levels within 72 hours, whereas in the nonsurvivor group, maximum levels were reached after 24 hours. Significant differences of Nt-proBNP were found only after 24 hours between survivors and nonsurvivors. Notably, NtproBNP revealed no predictive value for the development of MOF. In a retrospective study with 58 patients with CS largely secondary to AMI, initial Nt-proBNP levels above the median were associated with worsened outcome [19]. However, Nt-proBNP levels were not analyzed serially. Next to the retrospective study design, the number of patients was small in particular if the cohort was further subdivided. Among the 47 patients who had AMI as the primary cause of CS, only in 33 patients was coronary revascularization performed, with a success rate of $85 \%$ [19]. In our study, revascularization was attempted in $94 \%$ of patients, with a success rate of $96 \%$, and an IABP was placed in all patients.

In patients with septic shock, IL-6 levels have been shown to correlate with disease severity and outcome [20]. However, elevations are not sepsis specific. It has been shown that patients with CS and manifest MOF exhibit similarly high IL-6 levels, as in patients with 
Table 5 Multivariate Cox proportional hazard ratios for 30-day mortality

\begin{tabular}{lll}
\hline & Hazard ratios $(\mathbf{9 5} \% \mathrm{Cl})$ & $\boldsymbol{P}$ value \\
\hline Age, per 10 years & $3.372(1.548-7.348)$ & 0.002 \\
$\mathrm{CPI}, 0.1 \mathrm{~W} / \mathrm{m}^{2}$ & $0.790(0.506-1.231)$ & 0.297 \\
Mean dose of catecholamines, & $1.013(0.997-1.028)$ & 0.116 \\
$10 \mu \mathrm{m} / \mathrm{min}$ & & \\
Lactate $\mathrm{T}_{0}, \mathrm{mM}$ & $1.007(0.839-1.209)$ & 0.939 \\
Creatinine $\mathrm{T}_{0}, \mathrm{mg} / \mathrm{dl}$ & $1.589(1.033-2.444)$ & 0.035 \\
$\mathrm{IL}-6 \mathrm{~T}_{0}, 100 \mathrm{pg} / \mathrm{ml}$ & $1.036(1.017-1.055)$ & $<0.0001$ \\
$\mathrm{PCT} \mathrm{T}_{0}, \mu \mathrm{g} / \mathrm{L}$ & $1.236(0.843-1.812)$ & 0.277 \\
\hline
\end{tabular}

Abbreviations as in Tables 1 through 4.

septic shock [10]. In the setting of AMI, IL-6 was identified as independent prognostic marker [21]. In the present study, IL-6 levels differed significantly between the survivor and nonsurvivor groups at the early points in time, in which the values at admission showed an impressive discrepancy. In accordance with that, univariate analysis confirmed the predictive value of IL- 6 for 30-day mortality at the early points in time. IL-6 levels at admission revealed the highest level of significance within the ROC analyses. A cut-off level of $307 \mathrm{pg} / \mathrm{ml}$ showed a very clear differentiation between survivors and nonsurvivors within the Kaplan-Meier curves, associated with a very high specificity of $98 \%$. Moreover, in contrast to Nt-proBNP, IL-6 levels at $\mathrm{T}_{0}$ and $\mathrm{T}_{1}$ were predictive for occurrence of MOF. Our data confirm the results of a small retrospective study with only initial measurements of IL- 6 that also showed an independent predictive value of IL-6 for 30-day mortality [11]. It is hypothesized that next to ischemic myocardium, whole body ischemia, endotoxin translocation from the gut, excessive vasopressor therapy, and noncardiac organ failure are also contributing factors to IL-6 release [22]. Possibly, IL-6 constitutes not only an innocent bystander of inflammatory activation, but also might be an aggravating factor because IL- 6 determines negative inotropic effects on the myocardium [23].

Several studies have demonstrated that elevated levels of PCT indicate bacterial infection accompanied by a systemic inflammatory reaction [12]. Nevertheless, PCT elevation has been documented in infection-independent systemic inflammatory reactions. In recent studies, PCT levels were found to correlate with the extent of coronary artery disease and adverse outcome [24]. In a retrospective study, CS patients showed high PCT concentrations, especially in the presence of MOF and in the absence of signs of infection [25]. In a further investigation, PCT values were significantly higher in CS patients compared with patients with uncomplicated AMI [26]. The prognostic relevance of PCT in CS was not evaluated. In our study, both survivors and nonsurvivors reached maximum levels of PCT at $\mathrm{T}_{1}$. Significant differences between the two groups were seen at $T_{1}$ and $T_{2}$ and were strongly associated with outcome. ROC analysis showed the highest accuracy of predicting 30-day mortality for PCT at $\mathrm{T}_{1}$ and $\mathrm{T}_{2}$ with a sensitivity and specificity between $80 \%$ and $90 \%$. Notably, when comparing the area under the curve of NtproBNP, IL-6, and PCT, at all points in time, PCT at $\mathrm{T}_{1}$ showed the highest value.

\section{Hemodynamics and organ failure as predictors of outcome}

Hemodynamic data, including $\mathrm{CO}$ and pulmonary wedge pressure, were shown to be the strongest predictors of death in the GUSTO CS trial [27]. In a retrospective analysis from the SHOCK trial registry, CPI was the strongest predictor of mortality [28]. In our study, hemodynamic measurements also showed a predictive value of CPI in the univariate but not multivariate analysis.

Impaired renal function is one of the strongest risk factors for cardiovascular mortality. In a retrospective analysis in patients with CS due to AMI, 33\% developed an AKI within 24 hours of shock onset and showed a significantly higher mortality rate than did patients without AKI [29]. In a recent prospective study of STEMI patients with CS, AKI occurred in $55 \%$ of patients, and the in-hospital mortality rate was significantly higher in patients developing AKI than in patients without AKI [30]. In our study with STEMI and also NSTEMI patients, AKI occurred in 36\% of patients during first 72 hours after admission. All measured parameters of renal insufficiency were clearly associated with worse outcome.

Irreversible MOF is the main cause of death in CS. Until now, only a few studies addressed the issue of MOF in patients with CS. In a small study, $35 \%$ of patients with CS exhibited MOF at admission categorized by the SOFA score, and an additional 20\% developed MOF later during the clinical stay [10]. In our study, $24 \%$ of patients fulfilled criteria of MOF with a highly significant difference to the disadvantage of nonsurvivors.

\section{IL-6 is the strongest independent predictor of 30-day mortality}

As the central finding of our study, multivariate analysis including age, creatinine, lactate, CPI, mean dose of catecholamines, and IL-6 or PCT showed independent predictive values for age, creatinine, and IL-6, in which IL-6 reached the highest level of significance. Therefore, IL-6 might be a useful marker to identify very early CS patients who are at high risk of worse outcome. In contrast, the relevance of Nt-proBNP as an early prognostic marker must be challenged. PCT showed also a highly significant impact but primarily after the very early phase of AMI and CS. 


\section{Conclusions}

The present study demonstrates that in patients with AMI and CS treated with immediate revascularization and IABP, the destination of IL- 6 at admission reliably predicts 30-day mortality. For clinical practice, it is noticeable that a cut-off level of $307 \mathrm{pg} / \mathrm{ml}$ is associated with a very high specificity but moderate sensitivity. In contrast, Nt-proBNP seemed to be of lower relevance.

In conclusion, selective measurements of circulating inflammatory markers allow early prognostic estimation of patients with CS due to AMI. Potential therapeutic and prognostic interventions modulating the systemic inflammatory reaction have to be analyzed in further studies.

\section{Key messages}

- Systemic inflammation is observed in many patients with cardiogenic shock due to myocardial infarction.

- Interleukin-6 represents a reliable independent very early prognostic marker of 30-day mortality with high specificity.

- Procalcitonin is a very reliable predictor of 30-day mortality 24 and 72 hours after admission, with high sensitivity and specificity.

\section{Abbreviations \\ AMI: acute myocardial infarction; CABG: coronary artery bypass graft; CPR: cardiopulmonary resuscitation; CS: cardiogenic shock; IL-6: interleukin-6; MOF: multiorgan failure; NSTEMI: non-ST-elevation myocardial infarction; Nt- proBNP: N-terminal pro-B-type natriuretic peptide; PCl: percutaneous coronary intervention; PCT: procalcitonin; SIRS: systemic inflammatory response syndrome; STEMI: ST-elevation myocardial infarction.}

\section{Authors' contributions}

RPA, UMB, GN, and JOS participated in the conception and design or analysis and interpretation of data. RPA, UMB, RF, VT, JWS, GN, and JOS drafted the manuscript or revised it critically for important intellectual content. RPA, UMB, GN, and JOS gave final approval of the manuscript. All authors read and approved the manuscript for publication.

\section{Competing interests}

The authors declare that they have no competing interests.

Received: 21 March 2012 Revised: 24 July 2012

Accepted: 13 August 2012 Published: 13 August 2012

\section{References}

1. Babaev A, Frederick PD, Pasta DJ, Every N, Sichrovsky T, Hochman JS: Trends in management and outcomes of patients with acute myocardial infarction complicated by cardiogenic shock; NRMI Investigators. JAMA 2005, 294:448-454.

2. Goldberg RJ, Spencer FA, Gore JM, Lessard D, Yarzebski J: Thirty-year trends (1975 to 2005) in the magnitude of, management of, and hospital death rates associated with cardiogenic shock in patients with acute myocardial infarction: a population-based perspective. Circulation 2009, 119:1211-1219.

3. Hochman JS, Sleeper LA, White HD, Dzavik V, Wong SC, Menon V, Webb JG, Steingart R, Picard MH, Menegus MA, Boland J, Sanborn T, Buller CE, Modur S, Forman R, Desvigne-Nickens P, Jacobs AK, Slater JN, LeJemtel TH: SHOCK Investigators: Should We Emergently Revascularize Occluded
Coronaries for Cardiogenic Shock: one-year survival following early revascularization for cardiogenic shock. JAMA 2001, 285:190-192.

4. Hochman JS, Sleeper LA, Webb JG, Dzavik V, Buller CE, Aylward P, Col J, White HD, for the SHOCK Investigators: Early revascularization and longterm survival in cardiogenic shock complicating acute myocardial infarction. JAMA 2006, 295:2511-2515

5. Reynolds HR, Hochman JS: Cardiogenic shock: current concepts and improving outcomes. Circulation 2008, 117:686-697.

6. Maisel AS, Krishnaswamy P, Nowak RM, McCord J, Hollander JE, Duc P Omland T, Storrow AB, Abraham WT, Wu AH, Clopton P, Steg PG, Westheim A, Knudsen CW, Perez A, Kazanegra R, Herrmann HC, McCullough PA, Breathing Not Properly Multinational Study Investigators: Rapid measurement of B-type natriuretic peptide in the emergency diagnosis of heart failure. N Engl J Med 2002, 347:161-167.

7. Heeschen C, Hamm CW, Mitrovic V, Lantelme NH, White HD, Platelet Receptor Inhibition in Ischemic Syndrome Management (PRISM) Investigators: N-terminal pro-B-type natriuretic peptide levels for dynamic risk stratification of patients with acute coronary syndromes. Circulation 2004, 110:3206-3212.

8. Rudiger A, Gasser S, Fischler M, Hornemann T, von Eckardstein A, Maggiorini M: Comparable increase of B-type natriuretic peptide and amino-terminal pro-B-type natriuretic peptide levels in patients with severe sepsis, septic shock, and acute heart failure. Crit Care Med 2006, 34:2140-2144.

9. Kohsaka S, Menon V, Lowe AM, Lange M, Dzavik V, Sleeper LA, Hochman JS: Systemic inflammatory response syndrome after acute myocardial infarction complicated by cardiogenic shock. Arch Intern Med 2005, 165:1643-1650.

10. Geppert A, Steiner A, Zorn G, Delle-Karth G, Koreny M, Haumer M, Siostrzonek $P$, Huber K, Heinz G: Multiple organ failure in patients with cardiogenic shock is associated with high plasma levels of interleukin-6. Crit Care Med 2002, 30:1987-1994

11. Geppert A, Dorninger A, Delle-Karth G, Zorn G, Heinz G, Huber K: Plasma concentrations of interleukin-6, organ failure, vasopressor support, and successful coronary revascularization in predicting 30-day mortality of patients with cardiogenic shock complicating acute myocardial infarction. Crit Care Med 2006, 34:2035-2042.

12. Becker KL, Snider R, Nylen ES: Procalcitonin assay in systemic inflammation, infection, and sepsis: clinical utility and limitations. Crit Care Med 2008, 36:941-952.

13. Bektas F, Soyuncu S, Gunduz I, Basarici I, Akbas H, Eken C: The value of procalcitonin, a novel inflammatory marker, in the diagnosis of myocardial infarction and evaluation of acute coronary syndrome patients. J Emerg Med 2011, 41:524-530.

14. Kafkas N, Venetsanou K, Patsilinakos S, Voudris V, Antonatos D, Kelesidis K, Baltopoulos G, Maniatis P, Cokkinos DV: Procalcitonin in acute myocardial infarction. Acute Card Care 2008, 10:30-36.

15. Hochman JS, Sleeper LA, Webb JG, Sanborn TA, White HD, Talley JD, Buller CE, Jacobs AK, Slater JN, Col J, McKinlay SM, LeLemtel TH: Early revascularization in acute myocardial infarction complicated by cardiogenic shock. N Engl J Med 1999, 341:625-634.

16. Mega JL, Morrow DA, De Lemos JA, Sabatine MS, Murphy SA, Rifai N, Gibson CM, Antman EM, Braunwald E: B-type natriuretic peptide at presentation and prognosis in patients with ST-segment elevation myocardial infarction: an ENTIRE-TIMI-23 substudy. J Am Coll Cardiol 2004, 44:335-339.

17. Ndrepepa G, Braun S, Mehilli J, von Beckerath N, Nekolla S, Vogt W, Schwaiger M, Schömig A, Kastrati A: N-terminal pro-brain natriuretic peptide on admission in patients with acute myocardial infarction and correlation with scintigraphic infarct size, efficacy of reperfusion, and prognosis. Am J Cardiol 2006, 97:1151-1156.

18. Vergès $B$, Zeller $M$, Desgrès $J$, Dentan $G$, Laurent $Y$, Janin-Manificat $L$, L'Huillier I, Rioufol G, Beer JC, Makki H, Rochette L, Gambert P, Cottin Y: High plasma $\mathrm{N}$-terminal pro-brain natriuretic peptide level found in diabetic patients after myocardial infarction is associated with an increased risk of in-hospital mortality and cardiogenic shock. Eur Heart J 2005, 26:1734-1741.

19. Jarai R, Fellner B, Haoula D, Jordanova N, Heinz G, Karth GD, Huber K, Geppert A: Early assessment of outcome in cardiogenic shock: relevance of plasma N-terminal pro-B-type natriuretic peptide and interleukin-6 levels. Crit Care Med 2009, 37:1837-1844. 
20. Pinsky MR, Vincent $J$, Deviere J, Alegre M, Kahn RJ, Dupont E: Serum cytokine levels in human septic shock: relation to multiple-system organ failure and mortality. Chest 1993, 103:565-575

21. Théroux P, Armstrong PW, Mahaffey KW, Hochman JS, Malloy KJ, Rollins S, Nicolau JC, Lavoie J, Luong TM, Burchenal J, Granger CB: Prognostic significance of blood markers of inflammation in patients with STsegment elevation myocardial infarction undergoing primary angioplasty and effects of pexelizumab, a C5 inhibitor: a substudy of the COMMA trial. Eur Heart J 2005, 26:1964-1970.

22. Shpektor A: Cardiogenic shock: the role of inflammation. Acute Card Care 2010, 12:115-118.

23. Finkel MS, Oddis CV, Jacob TD, Watkins SC, Hattler BG, Simmons RL: Negative inotropic effects of cytokines on the heart mediated by nitric oxide. Science 1992, 257:387-389.

24. Sinning CR, Sinning JM, Schulz A, Schnabel RB, Lubos E, Wild PS, Papassotiriou J, Bergmann A, Blankenberg S, Munzel T, Bickel C, AtheroGene Study Investigators: Association of serum procalcitonin with cardiovascular prognosis in coronary artery disease. Circ J 2011, 75:1184-1191.

25. Geppert A, Steiner A, Delle-Karth G, Heinz G, Huber K: Usefulness of procalcitonin for diagnosing complicating sepsis in patients with cardiogenic shock. Intensive Care Med 2003, 29:1384-1389.

26. Picariello C, Lazzeri C, Chiostri M, Gensini G, Valente S: Procalcitonin in patients with acute coronary syndromes and cardiogenic shock submitted to percutaneous coronary intervention. Int Emerg Med 2009, 4:403-408.

27. Hasdai D, Holmes DR Jr, Califf RM, Thompson TD, Hochman JS, Pfisterer M Topol EJ: Cardiogenic shock complicating acute myocardial infarction: predictors of death. Am Heart J 1999, 138:21-31.

28. Fincke R, Hochman JS, Lowe AM, Menon V, Slater JN, Webb JG, LeLemtel TH, Cotter G: Cardiac power is the strongest hemodynamic correlate of mortality in cardiogenic shock: a report from the SHOCK trial registry: SHOCK Investigators. J Am Coll Cardiol 2004, 44:340-348.

29. Koreny M, Karth GD, Geppert A, Neunteufl T, Priglinger U, Heinz G, Siostrzonek P: Prognosis of patients who develop acute renal failure during the first 24 hours of cardiogenic shock after myocardial infarction. Am J Med 2002, 112:115-119.

30. Marenzi G, Assanelli E, Campodonico J, De Metrio M, Lauri G, Marana I, Moltrasio M, Rubino M, Veglia F, Montorsi P, Bartorelli AL: Acute kidney injury in ST-segment elevation acute myocardial infarction complicated by cardiogenic shock at admission. Crit Care Med 2010, 38:438-444.

doi:10.1186/cc11467

Cite this article as: Andrié et al:: Interleukin- 6 is the strongest predictor of 30-day mortality in patients with cardiogenic shock due to myocardial infarction. Critical Care 2012 16:R152.

\section{Submit your next manuscript to BioMed Central and take full advantage of:}

- Convenient online submission

- Thorough peer review

- No space constraints or color figure charges

- Immediate publication on acceptance

- Inclusion in PubMed, CAS, Scopus and Google Scholar

- Research which is freely available for redistribution

Submit your manuscript at www.biomedcentral.com/submit
C Biomed Central 